\title{
URBAN HEAT ISLAND: SUMMER OUTDOOR CLIMATE MEASUREMENT WITHIN THE UNIVERSITY CAMPUS AND CITY
}

\author{
Peter JURAS ${ }^{1, *}$ \\ ${ }^{1}$ Department of Building Engineering and Urban Planning, Faculty of Civil Engineering, University of \\ Zilina, Univerzitna 8215/1, 01026 Zilina, Slovakia. \\ corresponding author: peter.juras@uniza.sk
}

\section{Abstract}

Work of researchers from various areas is focused on problematics of urban heat islands. Its importance is rising with the global climate change. The difference of the air temperatures within the area can be also caused by the measurement error. Usual error is not the accuracy of the sensor, but the radiation shield or location of the weather station. In this case, averaged difference can be up to $80 \%$. Difference of temperatures between the weather stations within the analyzed area can vary from 0.2 up to $6^{\circ} \mathrm{C}$. Difference depends usual on the size of the city and the location influenced by the surrounding geomorphology. In this paper three different radiation shields are compared which influenced the measurement and analyzed are also the results from four different weather stations, two of them are within the University of Zilina campus. One of them is placed on the roof, which is a usual location for the solar radiation measurement; the second one is placed on the grass land at the end of the campus. Other two stations belong to the national weather institute. Comparison is made for two very hot days of August 2020. Averaged difference was $0.3{ }^{\circ} \mathrm{C}$ for the whole month and $0.5{ }^{\circ} \mathrm{C}$ for selected days.
\end{abstract}

Keywords:

Climate change; Mitigation;

Urban heat island;

Weather station;

Radiation shield.

\section{Introduction}

Outdoor climate is an important part of the set-up of simulation in civil engineering of any kind (heat-air moisture transport, heat and cool demand, overheating, etc.). Not only detailed outdoor boundary conditions [1-3], but also the material properties of used materials [3-6] and the used simulation tool and appropriate model from vast selection are important [7]. Several works deal with the accuracy of used outdoor climate $[1,2,6,7]$. Outdoor climate is highly influenced by existence of the urban heat island $(\mathrm{UHI})$. Urban climate is a rapidly expanding research field. More and more cities have been studied in terms of urban climate (mostly air temperature) and surface urban heat island (SUHI) patterns]. Amount of studies regarding $\mathrm{UHI}$ are constantly rising: too little UHI studies before 1990, 30 studies per year among 1990 and 2000, 100 studies per year in 2010, and more than 300 per year in 2015 [8]. First studies were published by meteorologists and environmental scientists. Since 2010 an interest in urban climate has rapidly expanded to other sectors, such as consideration for energy, engineering, and building construction issues has grown. These fields have often been most interested in technical solutions focused on reducing (mitigating) urban heat [9]. There is also renewed focus on the effects which cities have on the modification of precipitation, especially how buildings' effect on wind and thermal effects of cities can modify thunderstorm evolution or direction (and hence the precipitation pattern) [10].

Existence of urban heat island is caused by several reasons, such as: dark surfaces absorb significantly more solar radiation, which causes urban concentrations of roads and buildings to heat more than suburban and rural areas during the day [11] materials commonly used in urban areas for pavement and roofs (concrete and asphalt) have significantly different thermal properties (heat capacity and thermal conductivity) and surface radiative properties (albedo and emissivity) than the 
surrounding rural areas. This causes a change in the energy budget (difference between energies) of the urban area, often leading to higher temperatures than surrounding rural areas [12]. Another major reason is the lack of evapotranspiration (for example, through lack of vegetation) in urban areas [13]. With a decreased amount of vegetation, cities also lose the shade and evaporative cooling effect of trees [14]. Other causes of a UHI are due to geometric effects. The tall buildings within many urban areas provide multiple surfaces for the reflection and absorption of sunlight, increasing the efficiency with which urban areas are heated. This is called the "urban canyon effect". Another effect of buildings is the blocking of wind, which also inhibits cooling by convection and prevents pollutants from dissipating. Waste heat from automobiles, air conditioning, industry, and other sources also contributes to the UHI.

Reduction of UHI or mitigation possibilities is green roof and facades [15], which have a lot of positive effects not only regarding UHI but also increasing thermal properties [16].

The UHI can be defined as either the air temperature difference (the canopy UHI) or the surface temperature difference (surface UHI) between the urban and the rural area. These two facts show slightly different diurnal and seasonal variability and have different causes [13].

The Intergovernmental Panel on Climate Change of the United Nations stated that "it is wellknown that compared to non-urban areas urban heat islands raise night-time temperatures more than daytime temperatures" [17]. For example, Barcelona, Spain is $0.2^{\circ} \mathrm{C}$ cooler for daily maxima and 2.9 ${ }^{\circ} \mathrm{C}$ warmer for minima than a nearby rural station [18]. First report of the UHI by Luke Howard, who is considered as first person who deals with $\mathrm{UHI}$ problematics, in the late 1810 s said that the urban center of London was warmer at night than the surrounding countryside by $2.1^{\circ} \mathrm{C}$ [19]. Though the warmer air temperature within the $\mathrm{UHI}$ is generally most apparent at night, urban heat islands exhibit significant and somewhat paradoxical diurnal behavior. The air temperature difference between the $\mathrm{UHI}$ and the surrounding environment is large at night and small during the day. For the surface temperatures, dealing with SUHI is the opposite true [20]. The urban heat island temperature difference is not only usually larger at night than during the day, but also larger in winter than in summer. This is especially true in areas where snow is common, as cities tend to hold snow for shorter periods. Comparison of measured temperatures with different ground surfaces in real world was made in China [21], Singapure [22], Australia [23] or France [24].

In this paper, the differences during summer are analyzed. August 2020 had average air temperature $19.9{ }^{\circ} \mathrm{C}$, nine days have higher temperature than $30{ }^{\circ} \mathrm{C}$ and only during one night was cooler than $10^{\circ} \mathrm{C}$. Very hot days in August 2020 were chosen, where maximum temperature was above $30{ }^{\circ} \mathrm{C}$ and the night temperature oscillated between $15-20^{\circ} \mathrm{C}$. Comparisons were made among four weather stations.

\section{Weather station}

In Slovakia, the Slovak Hydrometeorological Institute (www.shmu.sk) has a network of 96 climatological stations. For this paper two of them were used, one is located in the city (named Zilina), another one is placed at the airport Zilina - Dolny Hricov (named Airport), which is out of the city (about $20 \mathrm{~km}$ far away) surrounded by meadows. This station was also used for the comparison in previous studies $[2,3,25,26]$ and due to effect of urban heat islands the measured values differ from the habituated area. Used weather stations (WS) are marked in Fig. 1 and 2.

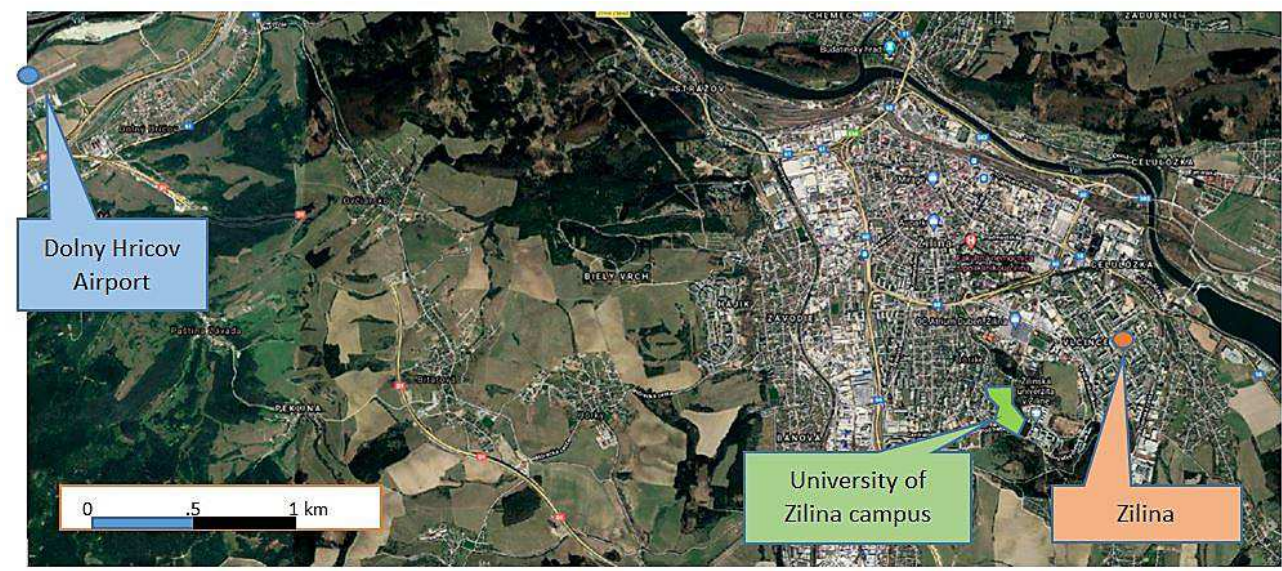

Fig. 1: Marked positions of SHMU weather stations and position of the University campus. 


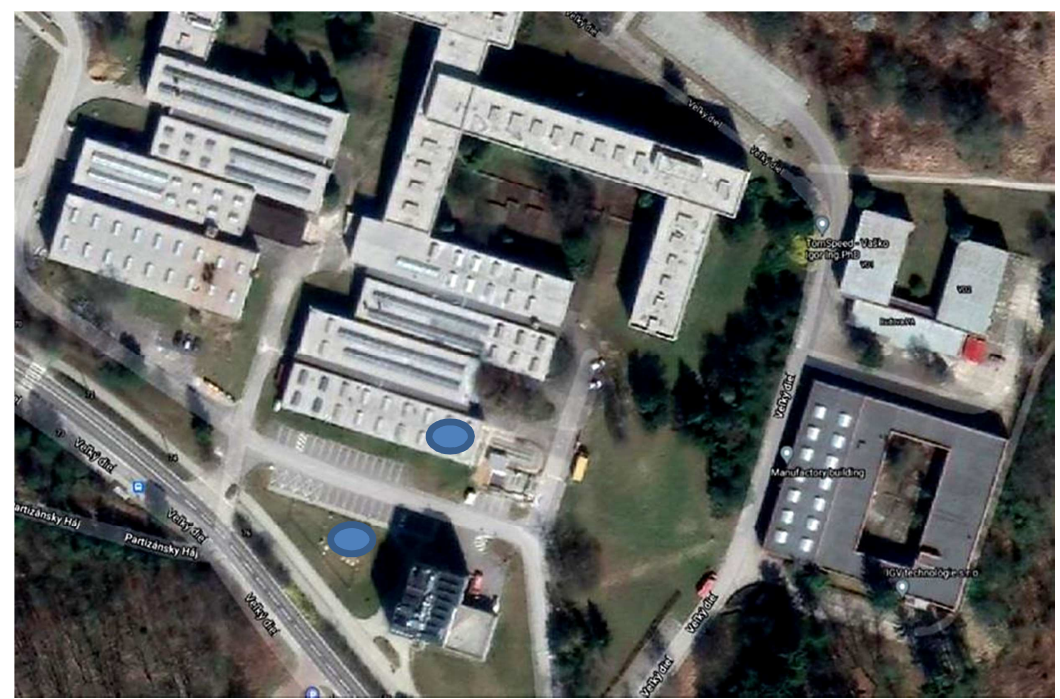

Fig. 2: Marked positions of University campus' weather stations used in this paper.

The University campus (UNIZA) is located in the suburbs of the city of Zilina and surrounded by the forest from three sides and meadow from the fourth one and slightly uphill compared to the rest of the city. Within the campus, there are several weather stations [27] of various quality, locations, measured climate parameter, etc. Also another universities use own weather stations nowadays, to increase the accuracy of comparison [1, 4]. Highlight is the special system of 36 façade meteorological stations on the building of Research centre [28] for monitoring the climate around the building façade. In this case, weather stations belonging to the Department of Building Engineering and Urban Planning were used; one of them is located on the roof of laboratory building. This station is working since 2017. Main reason for obtaining own weather station was to have as accurate outdoor climate for the lightweight wooden walls and windows research as possible and the opportunity to conduct simulations [7, 29-30]. Weather station was developed as prototype by the company Kvant and uses Sensirion SHT21 sensor for temperature/relative humidity measurement. Recording period is one minute. Another WS is in front of the laboratory building, in newly created observing station respecting some of the WMO guidelines [32] and measurements at urban sites requirements [33]. The manufacturer is Ahlborn and the device consist of the Meteo-Multisensor FMA-510 (which is in fact manufactured by Vaisala), which measures temperature, relative air humidity, air pressure, wind velocity and direction and rainfall. All devices are connected to the Almemo 2590 datalogger. Recording time step was set to one minute. Multiple sensors of the WS are regularly calibrated according to the manufacturer prescription in accredited laboratory. Relative humidity sensors often need to be shifted ( $8 \%$ of relative humidity during the years). Other sensors are more or less stable with small variance. Both weather stations are shown in Fig. 3.
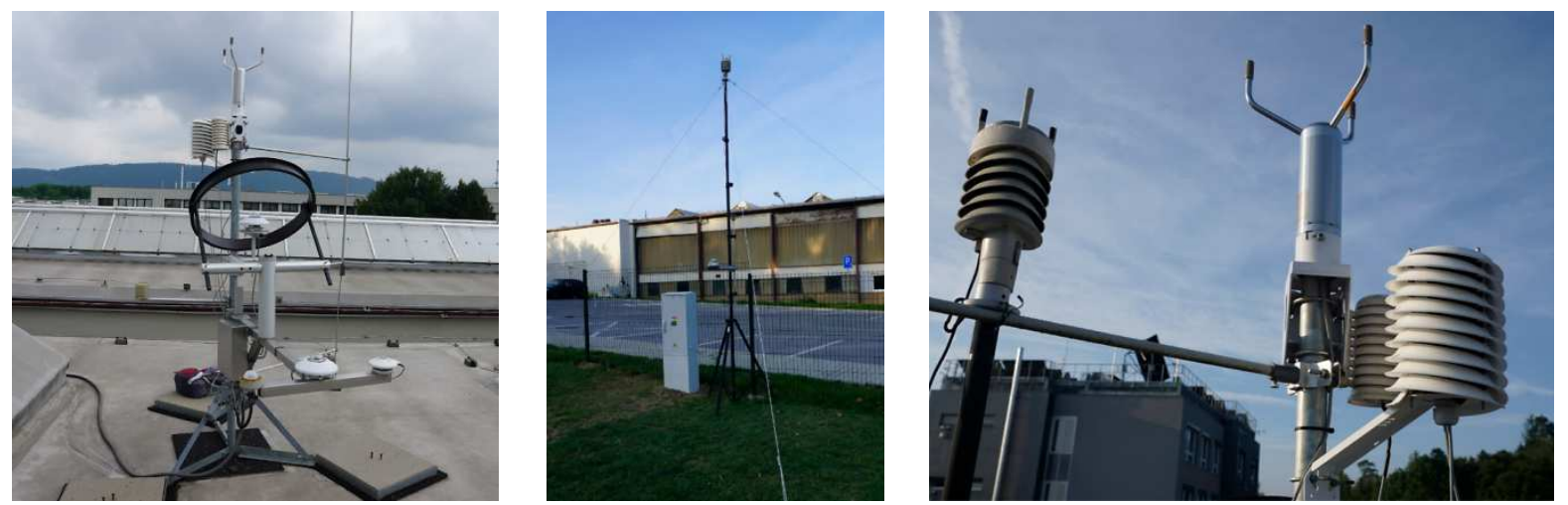

Fig. 3: Weather stations in the Campus: station on the roof, WS in the garden and picture from the radiation shield effectivity measurement.

SHMU uses automated weather station AWS Milos 500 from Vaisala and from Microstep MIS. Both stations are presented in Fig. 4. The exact location of the station is shown in Table 1. 

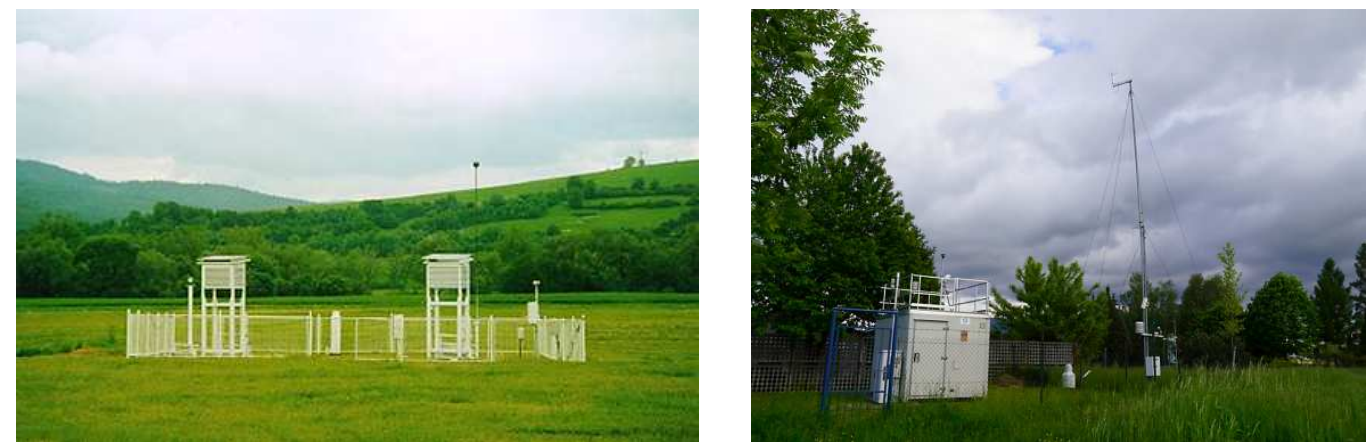

Fig. 4: Weather station belonging to SHMU network: Dolny Hricov Airport and Zilina.

Table 1: Location of the weather station.

\begin{tabular}{|c|c|c|c|}
\hline Name & Longitude & Latitude & Altitude A.S.L. [m] \\
\hline UNIZA WS ON THE ROOF & $18.756360^{\circ}$ & $49.201220^{\circ}$ & 405 \\
\hline UNIZA WS GRASS & $18.756130^{\circ}$ & $49.200887^{\circ}$ & 397 \\
\hline SHMU ZILINA & $18.771111^{\circ}$ & $49.211405^{\circ}$ & 358 \\
\hline SHMU DH AIRPORT & $18.614189^{\circ}$ & $49.232442^{\circ}$ & 310 \\
\hline
\end{tabular}

\section{Radiation shields and calibration}

Three radiation shields (RS) were tested before the comparison. Firstly, no name RS used by default on the WS on the roof were compared with the Ahlborn's weather station on the roof. Both sensors / shields were around $0.5 \mathrm{~m}$ from each other (right picture in Fig. 3). Results of this comparison are shown in Fig. 5. It can be clearly seen, that during the night the difference in temperatures is oscillating near the zero. During the day, as the solar radiation increases, difference is growing up to $4{ }^{\circ} \mathrm{C}$. This proves total unacceptability of that RS (in Fig. 5 name Radiation shield B). Influence of the measured relative humidity $(\mathrm{RH})$ is presented in Fig. 6. Here, the difference is opposite, highest different is during the night. Also the course is more balancing as the changes in the $\mathrm{RH}$ don't show so quickly.

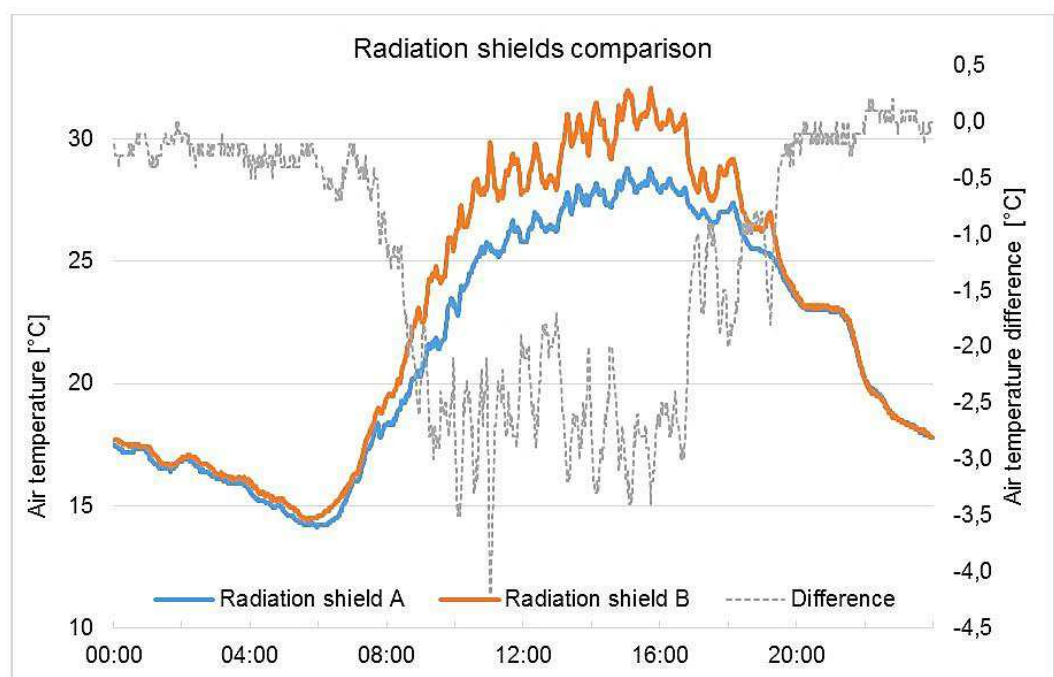

Fig. 5: Comparison of measured temperatures with radiation shields $A$ and $B$ during a sunny day.

The shield is too compact and the natural ventilation is not sufficient. Therefore, the original sensor was placed into another RS, developed by the Barani Design, MeteoShield Professional [34]. Comparison by third institutions stated $0.2{ }^{\circ} \mathrm{C}$ overheating compared to the others. Results of temperature comparison are in Fig. 7 and relative humidity in Fig. 8. Difference during the night is around $0.4{ }^{\circ} \mathrm{C}$ and during the day it is around $0.3^{\circ} \mathrm{C}$ (difference during the night is positive, during the day negative). This means that the sensor measured lower temperature during the high solar radiation than the one from Ahlborn. Daily averaged difference between the shields $A$ and $B$ is $1.2{ }^{\circ} \mathrm{C}$, after 
change of shield it dropped to $0.26{ }^{\circ} \mathrm{C}$. Relative humidity comparison showed similar courses with changing differences during the day. So the results are much more comparable, best match is in temperature measurement. The weather station on the roof after this calibrations comparison remains with the Radiation shield C (weather station remains the same, only RS was changed [34]). Results showed that radiation shield or screen is influencing the measured temperature more than the accuracy of the used sensor itself.

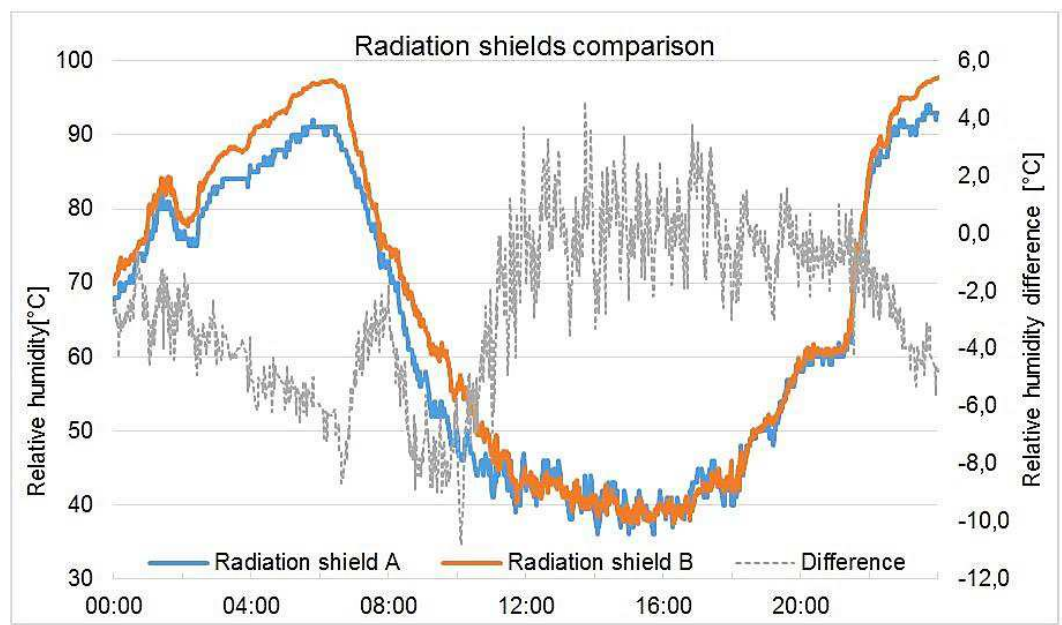

Fig. 6: Comparison of measured relative humidity with radiation shields $A$ and $B$ during a sunny day.

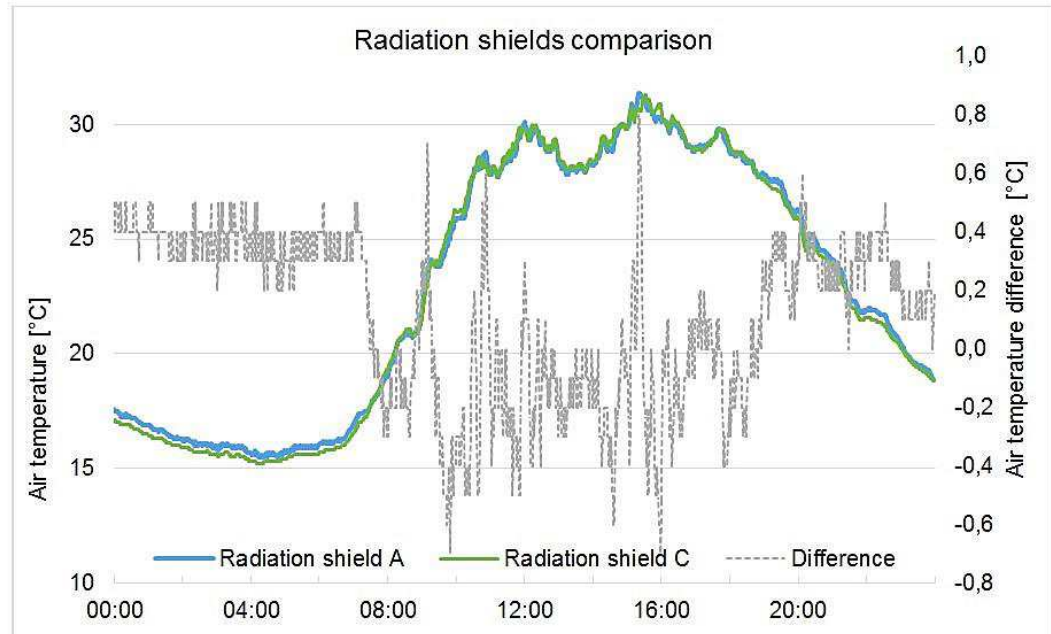

Fig. 7: Comparison of measured temperatures with radiation shields $A$ and $C$ during a sunny day.

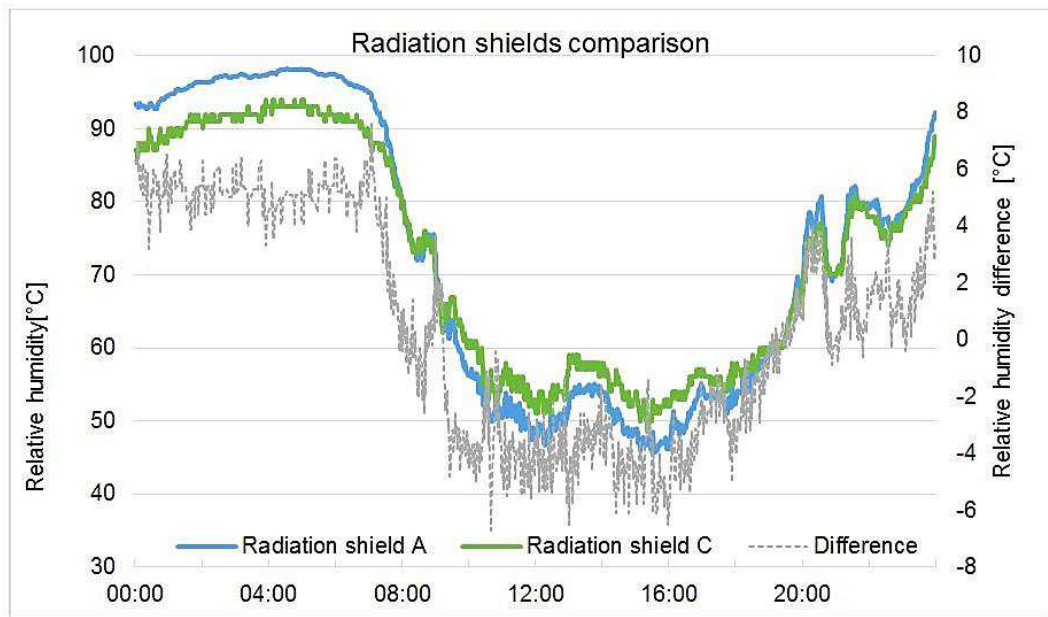

Fig. 8: Comparison of measured relative humidity with radiation shields $A$ and $C$ during a sunny day. 


\section{University campus comparison}

After the calibration comparison of the two weather stations, the Ahlborn's WS was moved to the new set up observation place in front of the building. Distance between the stations is around 40 m. In Fig. 9 temperature courses on August $21-22,2020$ are shown. Averaged difference is $0.57^{\circ} \mathrm{C}$. Rooftop weather station has higher increase of temperature and also lower decrease. Relative humidity comparison is in Fig. 10 and it showed and confirmed the fact, that the rooftop places are much drier [33] than the normal place on the ground. Results also correspond with the previous calibration comparison, so it is not the sensor or shield issue. Average from absolute values is $5 \%$.

This two selected days, especially the second one has also high night temperature, which means that the radiative cooling from the sky was limited. Rooftop WS has almost all time higher temperature and daily and night minimum too. Similar results are also in the other days during the whole month. Table comparison of the averages is shown in Table 2.

\section{Greater Zilina comparison}

Comparison between University of Zilina campus and SHMU stations is in Fig. 11 in term of temperature courses for the same days, August $21-22,2020$. The differences are calculated between the WS on the grass and those two stations on different locations. This is due to the placement, both SHMU stations are places on the ground covered by the grass, even the one in the city. Differences between the Airport's WS are higher, which confirms the fact, that the unhabituated, or less habituated areas has lower temperatures. On the other hand, between the WS Grass and WS Zilina is also difference, but not as high as in the previous case. In Fig. 12 are also temperature courses, but for August 7 and 8 . In this case, night temperature is higher at the Airport WS, it is probably caused by the clouds or mist. Averages of temperatures for selected days and the whole month are in Table 2 and 3.

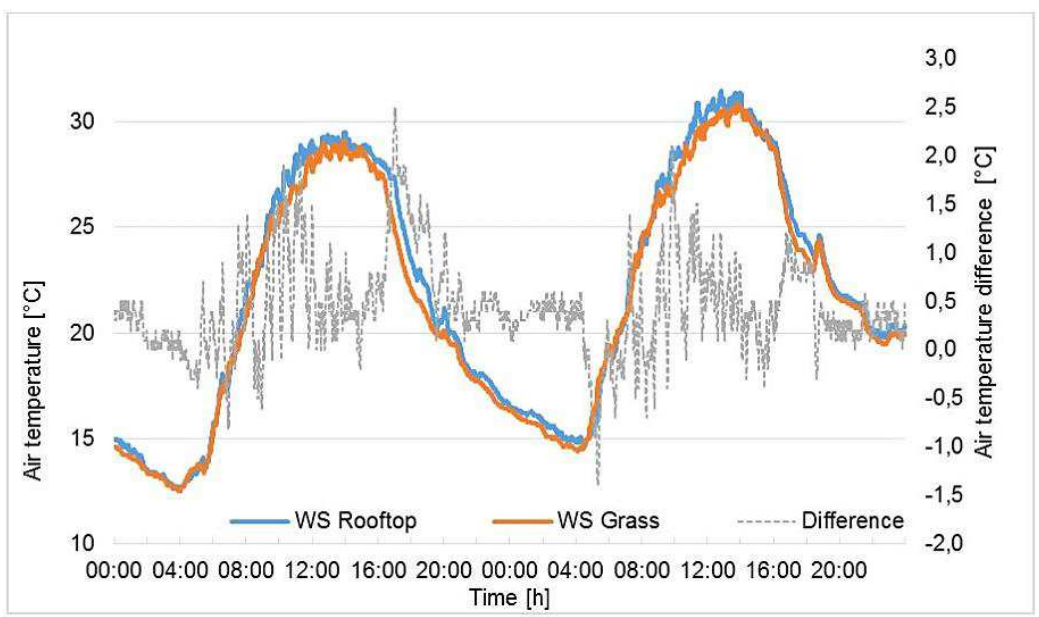

Fig. 9: Temperature courses for different weather stations on August 21 - 22, 2020.

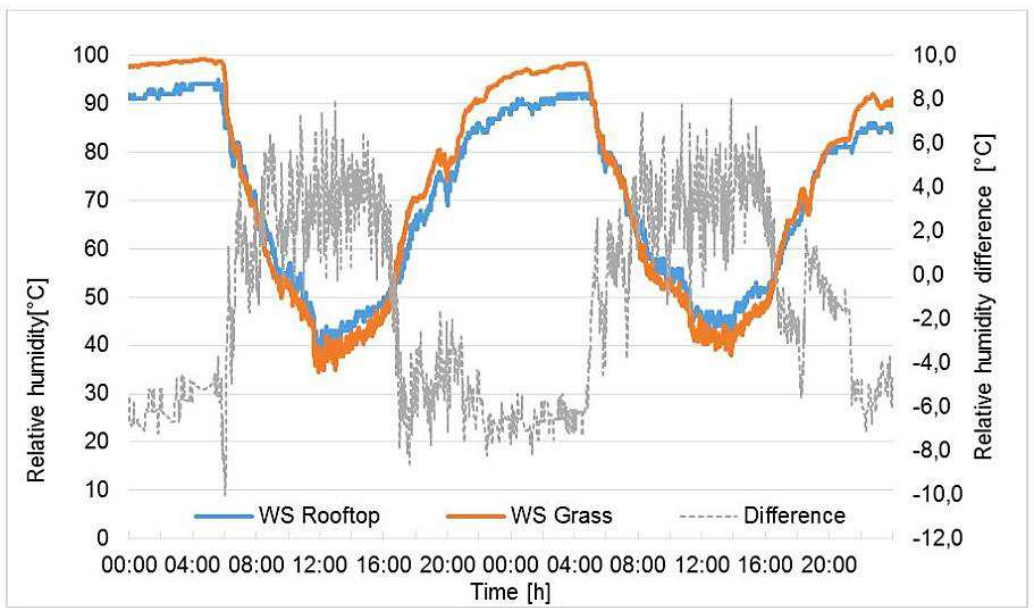

Fig. 10: Relative humidity courses for different weather stations on August $21-22,2020$. 


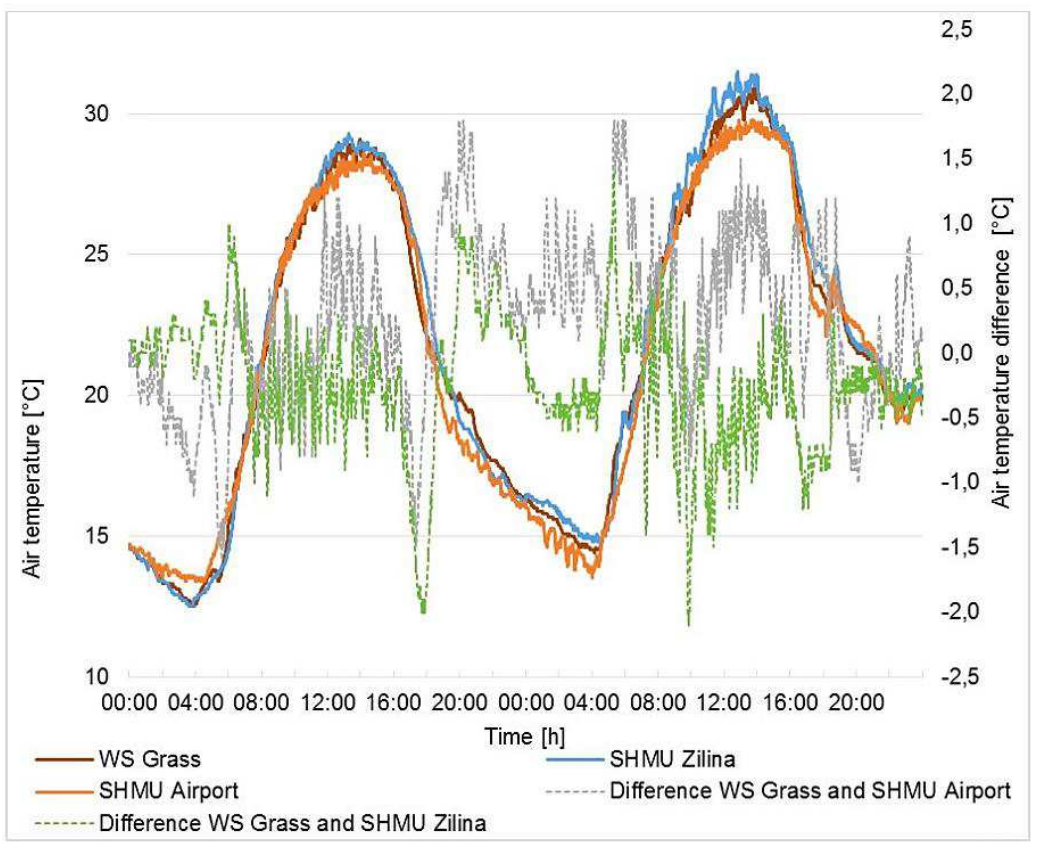

Fig. 11: Temperature courses for different weather stations on August 21 -22, 2020.

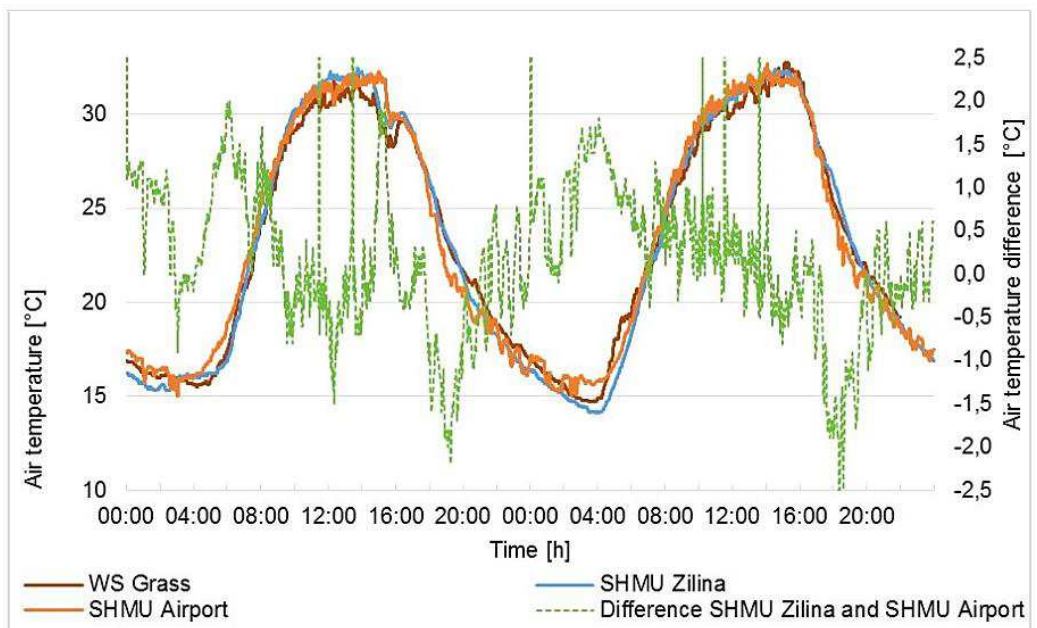

Fig. 12: Temperature courses for different weather stations on August 7-8, 2020.

Table 2: Monthly averages from compared weather stations.

\begin{tabular}{|c|c|c|c|c|}
\hline August 2020 & WS Rooftop & WS Grass & SHMU Zilina & SHMU Airport \\
\hline Air temperature $\left[{ }^{\circ} \mathrm{C}\right]$ & 20.2 & 19.9 & 20.1 & 19.8 \\
\hline Max. air temperature $\left[{ }^{\circ} \mathrm{C}\right]$ & 33.1 & 32.8 & 32.5 & 32.7 \\
\hline Min. air temperature $\left[{ }^{\circ} \mathrm{C}\right]$ & 7.9 & 7.8 & 7.4 & 7.5 \\
\hline Relative air humidity $[\%]$ & 71.6 & 72.7 & 77.8 & 74.6 \\
\hline Wind velocity $[\mathrm{m} / \mathrm{s}]$ & 0.95 & 0.70 & - & - \\
\hline
\end{tabular}


Table 3: Daily averages for selected days from compared weather stations.

\begin{tabular}{|c|l|c|c|c|c|}
\hline Day & & WS Rooftop & WS Grass & SHMU Zilina & SHMU Airport \\
\hline \multirow{4}{*}{ August 6 - 10 } & Air temperature $\left[{ }^{\circ} \mathrm{C}\right]$ & 23.1 & 22.6 & 22.6 & 22.8 \\
\cline { 2 - 6 } & Relative air humidity [\%] & 67.5 & 67.8 & 73.7 & 68.9 \\
\cline { 2 - 6 } & Wind velocity [m/s] & 0.8 & 0.6 & & \\
\hline \multirow{3}{*}{ August 21 } & Air temperature $\left[{ }^{\circ} \mathrm{C}\right]$ & 21.16 & 20.6 & 20.8 & 20.6 \\
\cline { 2 - 6 } & Relative air humidity [\%] & 70.5 & 72.6 & 76.8 & 74.1 \\
\cline { 2 - 6 } & Wind velocity $[\mathrm{m} / \mathrm{s}]$ & 0.79 & 0.50 & - & - \\
\hline \multirow{3}{*}{ August 22 } & Air temperature $\left[{ }^{\circ} \mathrm{C}\right]$ & 23.1 & 22.5 & 22.7 & 22.3 \\
\cline { 2 - 6 } & Relative air humidity [\%] & 70.4 & 71.4 & 76.8 & 74.1 \\
\cline { 2 - 6 } & Wind velocity [m/s] & 0.89 & 0.6 & & \\
\hline
\end{tabular}

\section{Discussion and results analysis}

Presented results can be divided into two parts: direct comparison of radiation shields showed their importance. Usually solar radiation heats up the shield and overestimated temperatures are measured, much higher than the accuracy of sensor and other deviations. Therefore it is very important to use the proper shield.

Second part is comparison of measurement in different locations and types of underground of the weather stations. Rooftop location showed highest temperatures, which is more results of the near habituated area than the roof location. Or it is combination of these two parts. The weather station on the grass, or in the observation area has the values between the Airport and Zilina WS locations. There were small differences, so there are many variables which can influence the results. Regarding the Study of heat mitigation from PBL Netherlands Environmental Assessment Agency [35], the county of Zilina has calculated UHI around $1.57^{\circ} \mathrm{C}$, but both location, UNIZA campus and also Zilina WS are in moderate area which is about $0.6^{\circ} \mathrm{C}$ above the coldest part.

In this study the temperature difference $0.5^{\circ} \mathrm{C}$ for hottest days and $0.3^{\circ} \mathrm{C}$ for the month was obtained.

\section{Conclusion}

In this paper, comparison of different radiation shields was conducted with significant result. With use of better shield, the difference can be lowered up to $80 \%$.

Regarding the temperature measurements at different locations in the area of Zilina, rooftop locations showed that it is the hottest one. The weather station located on the grass of the meteorological observation garden has similar results as the weather station located at the airport outside the city.

Depending on the source and author, the size of the effects depends on the size of the city [36] and also on other variables. For example, variation in Bratislava was observed up to $4{ }^{\circ} \mathrm{C}$ during the day [37]. In this study, as stated before only fixed WS were used and not in the most habituated areas, so this is certainly not the worst scenario.

In the future, also winter season will be compared, because UHI can be more severe during winter.

\section{Acknowledgement}

The research is supported by the research project VEGA No. 1/0673/20, UNIZA Grant scheme No. 6425 and also with provided data from Slovak Hydrometeorological Institute in Bratislava (SHMU).

\section{References}

[1] KATUNSKY, D. et al.: Experimentally Measured Boundary and Initial Conditions for Simulations. Advanced Materials Research, Vol. 1041, 2014.

[2] STAFFENOVA, D. - PONECHAL, R.: Comparison of meteorological climate data sets from Greater Žilina and their influence on temperatures within the experimental wall. Applied Mechanics and Materials, Vol. 861, 2016. 
[3] STAFFENOVA, D. et al.: Importance of using the right climate data sets for needs of energy analysis and choosing the accurate building materials. Modern materials and technologies in sustainable building (monograph), 2014, pp. 45-53.

[4] VERTAL, M. et al.: Case study investigations on drying process cellular concrete external walls with ETICS (in German). Bauphysik, 38, 2016, pp. 378-388.

[5] DURICA, P. - VERTAL, M.: Verification of the water transport parameter - Moisture storage function of autoclaved aerated concrete - Approximately calculated from a small set of measured characteristic values. Communications, Vol. 13, Iss. 4, 2011, pp. 92-97.

[6] VERTAL, M. et al.: Hygrothermal initial condition for simulation process of green building construction. Energy and Building, Vol. 167, 2018, pp. 166-176.

[7] JURAS, P. - PONECHAL, R.: Measurement of lightweight experimental wall and comparison with different simulation programs. Applied mechanics and materials, Vol. 820, 2016, pp. 262-269.

[8] HUANG, Q. - LU, Y.: Urban heat island research from 1991 to 2015: a bibliometric analysis. Theor. Appl. Climatol, Vol. 131, 2018, pp. 1055-1067.

[9] PHELAN, P. E. et al.: Urban heat island: mechanisms, implications, and possible remedies. Annu. Rev. Environ. Resour., Vol. 40, 2018, pp. 285-307.

[10] MASSON, V. et al.: Urban Climates and Climate Change. Annual Review of Environment and Resources, Vol. 45, 2020, pp. 411-444.

[11] SOLECKI, W. D. et al.: Mitigation of the heat island effect in urban New Jersey. Global Environmental Change Part B: Environmental Hazards, Vol. 6 (1), 2005, pp. 39-49.

[12] OKE, T. R.: The energetic basis of the urban heat island. Quarterly Journal of the Royal Meteorological Society, Vol. 108, 1982, pp. 1-24.

[13] KUMAR, R. et al.: Dominant control of agriculture and irrigation on urban heat island in India. Scientific Reports, Vol. 7 (1), 2017.

[14] GORSEVSKI, V. et al.: Air Pollution Prevention Through Urban Heat Island Mitigation: An Update on the Urban Heat Island Pilot Project. United States. NASA.

[15] BESIR, A. B. - CUCE, E.: Green roofs and facades: A comprehensive review. Renewable \& Sustainable energy reviews, 2018.

[16] TUDIWER, D. et al.: Illustration of the heat-insulating effect of a façade greening system in a simulation. Bauphysik, Vol. 41, Iss. 3, 2019.

[17] IPCC Climate Change 2001: The Scientific Basis. Chapter 2.2 How Much is the World Warming?

[18] GARCIA, C. M.: Intensity and form of the urban heat island in Barcelona. International Journal of Climatology, Vol. 14 (6), 1993, pp. 705-710.

[19] HEIDORN, K. C.: Luke Howard: The Man Who Named The Clouds. Islandnet.com. Retrieved 2009-06-18.

[20] ROTH, M. - OKE, T. R. - EMERY, W. J.: Satellite-derived urban heat islands from three coastal cities and the utilization of such data in urban climatology. International Journal of Remote Sensing, Vol. 10 (11), 1989, pp. 1699-1720.

[21] HUANG, Z. - GOU, Z. - CHENG, B.: An investigation of outdoor thermal environments with different ground surfaces in the hot summer-cold winter climate region. Journal of Building Engineering, Vol. 27, 2020.

[22] YU, Z. et al.: Dependence between urban morphology and outdoor air temperature: A tropical campus study using random forests algorithm. Sustainable Cities and Society, Vol. 61, 2020.

[23] KENAWY, I. et al: Summer outdoor thermal benchmarks in Melbourne: Applications of different techniques. Building and Environment, Vol. 195, 2021.

[24] BERNARD, J. et al: Urban heat island temporal and spatial variations: Empirical modeling from geographical and meteorological data. Building and Environment, Vol. 125, pp. 423-438.

[25] JURASOVA, D.: Analysis of long-term measured exterior air temperature in Zilina. Civil and Environmental Engineering, Vol. 14, Iss. 2, 2018, pp. 124-131.

[26] STAFFENOVA, D. et al.: Climate data processing for needs of energy analysis. Advanced Materials Research, Vol. 1041, 2014.

[27] JURAS, P. - JURASOVA, D.: Outdoor climate change analysis in university campus. Civil and Environmental Engineering, Vol. 16, Iss. 2, 2020, pp. 370-378.

[28] JURAS, P. - PONECHAL, R. - STAFFENOVA, D.: Initial results of monitoring the temperature on the facade of office building. Applied Mechanics and Materials, Vol. 887, 2019, pp. 411-418.

[29] MICHALKOVA, D. - DURICA, P.: Analysis of the influence of the selected exterior surface finish on the thermo-technical behaviour of passive wooden constructions. Transportation Research Procedia, Vol. 40, 2019, pp. 823-830. 
[30] STAFFENOVA, D. et al.: Intention, Principle, Outputs and Aims of the Experimental Pavilion Research of Building Envelopes Including Windows for Wooden Buildings. Civil and Environmental Engineering, Vol. 13, Iss. 1, 2017, pp. 42-51.

[31] JURAS, P. et al.: Comparison of different windows for low-energy houses. MATEC Web of Conferences, Vol. 117, 2017.

[32] World Meteorological Organization: Guide to Instruments and Methods of Observation. WMO: 2018.

[33] OKE, T. R.: Siting and Exposure of Meteorological Instruments at Urban Sites. Air Pollution Modeling and Its Application XVII, 2007.

[34] https://www.baranidesign.com/meteoshield-professional.

[35] PBL Netherlands Environmental Assessment Agency: https://naturvation.eu/content/europeanassessment-maps.

[36] United States. Environmental Protection Agency. Heat Island Effect. By EPA. N.p., 29 August 2013. Web. 31 August 2015. <http://www.epa.gov/heatisld/about/index.htm.

[37] HOLEC, J. - GARAJ, M. - PECHO, J.: Influence of the built environment on the air temperature regime in Bratislava (In Slovak). http://www.shmu.sk/sk/?page=2049\&id=939. 